\title{
2007 Survey of Medical Toxicology Practice Improvement Activities
}

\author{
Suzanne R. White • Beth Baker • Carl R. Baum • Anne Harvey • Robert Korte • \\ A. Nelson Avery $\cdot$ Lewis Nelson $\cdot$ Kevin Osterhoudt $\cdot$ Curtis Snook $\cdot$ Saralyn Williams
}

Published online: 17 March 2010

(C) American College of Medical Toxicology 2010

\begin{abstract}
To date, there appear to be no studies that assess Medical Toxicologists' (MTs) practice improvement (PI) activities in their Medical Toxicology practice settings. The MT Assessment of Practice Performance (APP) Taskforce queried all MT diplomates about (1) activities currently available in their practice settings that potentially would meet the requirements of APP, (2) potential APP activities that best fit with current MT practice, and (3) the relationship between MT practice patterns and APP requirements. One hundred twenty-seven surveys were completed. Participation in MT practice improvement activities is not universal, with approximately a third of the survey participants reporting that they are not involved in any practice improvement activity. Few respondents reported that they collected performance improvement-related data. Most who did so participated in CME, case, or chart reviews. Peer reviews, self-improvement plans based on chart reviews, and population research were considered the most valid measures of MT practice improvement. Communication
\end{abstract}

S. R. White · A. Harvey • R. Korte · L. Nelson • C. Snook •

S. Williams

American Board of Emergency Medicine,

East Lansing, MI, USA

B. Baker · A. N. Avery

American Board of Preventive Medicine,

Chicago, IL, USA

C. R. Baum $\cdot$ K. Osterhoudt

American Board of Pediatrics,

Chapel Hill, NC, USA

S. R. White $(\square)$

3R Emergency Medicine, Detroit Receiving Hospital,

4201 St. Antoine,

Detroit, MI 48201, USA

e-mail: swhite1@dmc.org skills were considered important topics for patient surveys. Suggested outcomes for peer assessment included accuracy of information provided, understanding medical staff concerns, timeliness of feedback, and helpfulness. Most respondents rated all of the APP options as being somewhat very intrusive. Access to those with sufficient knowledge of the diplomate's practice improvement program to verify APP could pose a challenge to a successful completion of APP requirements. Optimal settings for the APP program administration are hospitals and poison centers. While barriers to MT APP activities exist, studying current MT diplomates' opinions and practices could inform the future development and administration of such programs.

Keywords Board certification - Maintenance of certification - Practice performance assessment . Medical toxicology

\section{Introduction}

In this era of increasing medical complexity and movement towards improved healthcare quality, Maintenance of Certification (MOC) $\odot$ has been designed to address the desire for greater public accountability in the practice of medicine. MOC is a commitment to diplomates' continuous improvement, leading to opportunities for providing better care.

Since 1999, the American Board of Medical Specialties (ABMS) and the ACGME have required that six core competencies for quality patient care be adopted by training programs and ABMS member boards: patient care, medical knowledge, interpersonal and communication skills, professionalism, systems-based practice, and practice-based learning and improvement. ABMS guides the MOC process for 24 Member Boards with a four-part process for 
continuous learning. Part I, Professional Standing, requires medical specialists to hold a valid, unrestricted medical license in at least one state or jurisdiction in the USA, its territories or Canada. Part II, Lifelong Learning and SelfAssessment (LLSA), requires participation in educational and self-assessment programs that meet specialty-specific standards. Part III, Cognitive Expertise, requires physicians to demonstrate, through formalized secure examination, that they have the fundamental, practice-related and practice environment-related knowledge to provide quality care in their specialty. Finally, in Part IV, Practice Performance Assessment, diplomates evaluate and improve their clinical practice according to specialty-specific standards for patient's care. They are asked to demonstrate that they can assess the quality of care they provide compared with peers and national benchmarks and then apply the best evidence or consensus recommendations to improve that care using follow-up assessments [1].

Medical Toxicology certification is sponsored by three ABMS primary specialty member boards-emergency medicine, pediatrics, and preventive medicine; all member boards of ABMS. Medical Toxicology was recognized by ABMS in 1994 when the first medical toxicology certification examination was given. Diplomates were required to maintain professional standing beginning in 2004, when the first cognitive expertise examination was also given. Beginning in 2006, a medical toxicology LLSA process was developed and the first LLSA examination was offered in 2009. Having addressed the first three parts of MOC, the Medical Toxicology Subboard was tasked in 2007 with the development of a Practice Performance Assessment Program. The Subboard was unable to locate any study that has assessed the population of ABMS medical toxicology diplomates (287 in 2007) relative to practice improvement in patient interaction or other practice issues. This type of information was determined to have critical relevance as practice evaluation tools were explored and developed.

\section{Methods}

In 2007, the Medical Toxicology Assessment of Practice Performance Task Force, on behalf of the Medical Toxicology Subboard, developed and conducted an online survey of all Medical Toxicology diplomates asking about their current practice settings. The first part of the survey asked about diplomates' practice settings in terms of the number of individual patients they saw or on whose behalf they consulted the most common diagnoses, and the percent of time spent in their roles as a medical toxicologist and in their primary specialty. These results are summarized elsewhere. The second part of the survey focused on assessing current practice improvement activities among diplomates. The survey was designed to collect information that would guide the Subboard by answering the following questions:

What activities are currently available in medical toxicologists' work settings that potentially would meet the requirements of APP?

What potential APP activities best fit with current Medical Toxicology practice and meet the requirements of APP?

What is the relationship between Medical Toxicology practice patterns and requirements to complete APP activities?

The final survey, which was administered via the internet, is presented in Fig. 1. An advanced notification letter was sent to 287 diplomates with the Internet address of the survey, their ID, and password. On October 26, 2007, a reminder postcard was sent to diplomates who had not yet completed the survey. A copy of this second part of the survey is shown in Fig. 1. The study was granted IRB Exemption (protocol 0905007159, Wayne State University Human Investigation Committee).

\section{Results}

One hundred twenty-seven surveys (44\%) were completed. This is similar to response rates observed with most social science surveys [2].

\section{Respondents by Primary Board}

The percent of diplomates in the population and the sample of diplomates who submitted surveys are presented by the primary board in Table 1 .

Eighty percent $(80 \%)$ of respondents listed their primary board as emergency medicine; $12 \%$ preventive medicine; and $7 \%$ pediatrics. These results indicate that the primary specialty of the sample of survey respondents is similar to that of the total population of Medical Toxicology diplomates: emergency medicine $(82 \%)$, preventive medicine $(10 \%)$, and pediatrics $(8 \%)$. Due to a program error on the first day of the survey, the primary boards of six respondents were not captured. The six are therefore not listed as part of the response rate by primary specialty.

\section{Current Practice Improvement Activities}

A modest 83 (65\%) respondents indicated that they participated in practice improvement activities as a medical toxicologist. With the exception of a question about affiliation with poison control centers, the remainder of the questions in this section was answered by only the 83 respondents participating in practice improvement activities. 


\section{Survey of Current Practice Medical Toxicology Practice Improvement Activities}

These questions are designed to obtain information about the types of Medical Toxicology practice improvement activities in which you participate. You may participate in activities in a variety of practice settings. Please respond to the questions in your role as a medical toxicologist. Practice improvement activities are quality improvement measures such as developing and implementing new patient treatment protocols or improving patient flow.

1. Do you personally participate in one or more practice improvement activities in any of the following settings? (Select All that Apply)

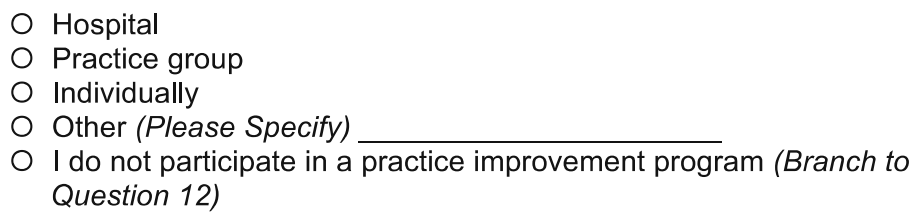

2. In what practice improvement activities do you participate? Is the activity mandated? (Select All that Apply)

$\underline{\text { Activities }}$

Patient chart review

Case review conference (m\&m or other)

Review by clinical support staff (RNs, PAs, etc.)

Patient satisfaction survey

Peer review survey

$360^{\circ}$ review

Self-initiated activities

Nationally sponsored program

Level $1 \mathrm{CME}$

Other (Please Specify)

Participate $\quad \frac{\text { Is This Mandated? }}{\text { Yes }}$

$\begin{array}{lll}0 & 0 & 0 \\ 0 & 0 & 0 \\ 0 & 0 & 0 \\ 0 & 0 & 0 \\ 0 & 0 & 0 \\ 0 & 0 & 0 \\ 0 & 0 & 0 \\ 0 & 0 & 0 \\ 0 & 0 & 0 \\ 0 & 0 & 0\end{array}$

3. Who is responsible for setting practice improvement standards in your practice setting? (Select All that Apply)

O Federal or state mandate such as CMS

$\mathrm{O}$ Credentialing mandate such as JCAHO

O Hospital board

O Hospital administrator

O Department chair

$O$ Medical director or chief of staff

O Physician's group

Other (Please Specify)

4. On what measures do your practice improvement activities focus? (Select All that Apply)

O There are no measures in place (Branch to Question 10)

O Patient access to services

O Patient satisfaction

O Patient care

O Communication

O Professionalism

Medical processes

O Patient outcomes

O JCAHO and/or CMS federal measures

O Other (Please Specify)

5. On which of the following were your practice improvement evaluations based?

Results from my practice

Data from my group or department

O Data is not collected

Fig. 1 Survey of current practice medical toxicology practice improvement activities 
6. Do the practice improvement activities in which you participate contain the following components? (Answer Each Separately)

\begin{tabular}{|l|c|c|}
\hline \multicolumn{1}{|c|}{ Component } & Yes & No \\
\hline $\begin{array}{l}\text { An initial evaluation of you or your group's practice that includes a sampling of } \\
\text { patients with a specific disease or clinical process }\end{array}$ & $\mathrm{O}$ & O \\
\hline Feedback on your own performance from the collected information & $\mathrm{O}$ & $\mathrm{O}$ \\
\hline $\begin{array}{l}\text { A comparison of the evaluation outcome to evidenced-based standards and/or } \\
\text { peer data }\end{array}$ & $\mathrm{O}$ & $\mathrm{O}$ \\
\hline Development of a personal or group practice improvement plan & $\mathrm{O}$ & $\mathrm{O}$ \\
\hline Follow-up assessment of the effect of the improvement plan & $\mathrm{O}$ & $\mathrm{O}$ \\
\hline
\end{tabular}

7. Do you work in a poison control center?

Yes (Branch to Question 8)

O No (Branch to Question 9)

8. Select the poison-control related evaluation activities in which you participate. (Select All that Apply)

Monitoring of patient outcomes in terms of risk, volume, and problemprone cases

O Development and implementation of corrective action to improve patient care

O Monitoring of poison control center user satisfaction

O Assessment of staff competency on an ongoing basis

\section{Potential APP Activities}

The Medical Toxicology Subboard is considering a number of options for Medical Toxicology Assessment of Practice Performance (APP). Answers to the remaining questions will help the Subboard to develop an APP program that will best meet the needs of Medical Toxicology diplomates.

9. For the measures listed below, indicate how valid you think each of the methods is for measuring practice performance improvement.

\begin{tabular}{|l|c|c|c|c|c|}
\hline $\begin{array}{l}\text { Methods of Practice } \\
\text { Performance }\end{array}$ & $\begin{array}{c}\text { Not } \\
\text { Valid }\end{array}$ & & $\begin{array}{c}\text { Somewhat } \\
\text { Valid }\end{array}$ & Highly Valid \\
\hline Peer review & 0 & 0 & 0 & 0 & 0 \\
\hline $\begin{array}{l}\text { Self-improvement plan based on } \\
\text { chart reviews }\end{array}$ & 0 & 0 & 0 & 0 & 0 \\
\hline Patient surveys & 0 & 0 & 0 & 0 & 0 \\
\hline $360^{\circ}$ evaluations & 0 & 0 & 0 & 0 & 0 \\
\hline $\begin{array}{l}\text { Specific outcomes (e.g. } \\
\text { malpractice claims/settlement } \\
\text { costs) }\end{array}$ & 0 & 0 & 0 & 0 & 0 \\
\hline Population research & 0 & 0 & 0 & 0 & 0 \\
\hline Other & 0 & 0 & 0 & 0 & 0 \\
\hline
\end{tabular}

10. In your experience, what are the most valuable topics for patient survey questions? (Select All that Apply)

O Overall evaluation of visit

O Helpfulness physician and staff

O Adequate time with physician

O Adequate pain relief

O Patient made comfortable

O Patient treated with respect

O Patient's main concern understood

O Information about tests/procedures provided and understood by patient

$O$ Effectiveness of treatment/ quality of care provided

O Clear explanations/communication from physician/medical staff

O Other (Please Specify)

Fig. 1 (continued) 
11. In your experience, what are the most valuable topics for peer survey questions? (Select All that Apply)

O Main concerns of physician/medical staff understood

O Gets back to physician/medical staff in a timely manner

O Helpfulness of the physician

Spends adequate time with physician/medical staff

O Physician/medical staff treated with respect

O Information about tests/procedures accurate

Information about recommended patient care treatment accurate

O Other (Please Specify)

12. Which of the following persons would be sufficiently knowledgeable about your practice improvement activities to verify that you have completed required activities? (Select All that Apply)

O Hospital board chair or member of the board

Department chair

O Chief of staff

O Medical director

O Practice administrator/supervisor in non-hospital settings

None of the above would be available (Branch to question 16)

13. Who would be an appropriate person to verify that you have completed your practice improvement activities?

14. How intrusive would the following activities be to your daily practice of Medical Toxicology?

\begin{tabular}{|l|c|c|c|c|c|}
\hline Practice Improvement Activities & $\begin{array}{c}\text { Not } \\
\text { Intrusive }\end{array}$ & $\begin{array}{c}\text { Somewhat } \\
\text { Intrusive }\end{array}$ & $\begin{array}{c}\text { Very } \\
\text { Intrusive }\end{array}$ \\
\hline $\begin{array}{l}\text { Obtain results from an existing } \\
\text { practice improvement program to } \\
\text { evaluate your performance }\end{array}$ & 0 & 0 & 0 & 0 & 0 \\
\hline $\begin{array}{l}\text { Create and implement a new } \\
\text { practice improvement program for } \\
\text { yourself only }\end{array}$ & 0 & 0 & 0 & 0 & 0 \\
\hline $\begin{array}{l}\text { Use a practice improvement } \\
\text { program requiring entry of patient } \\
\text { chart data }\end{array}$ & 0 & 0 & 0 & 0 & 0 \\
\hline $\begin{array}{l}\text { Collect data on the outcomes of a } \\
\text { population health program }\end{array}$ & 0 & 0 & 0 & 0 & 0 \\
\hline
\end{tabular}

Comments:

Fig. 1 (continued)

Respondents were asked to indicate all the settings in which they participated in practice improvement activities. When asked to select all of the settings in which they participate, the majority (69\%) indicated that they participated in a hospital setting with $42 \%$ indicating they participated as part of their practice group and $40 \%$ individually. Another $18(22 \%)$ respondents indicated that they participated in a poison control center. Together, the hospital and poison control center settings made up a large portion of the potential settings for practice improvement activities.

The types of activities in which respondents participate varied, with case review conferences $(87 \%)$, level $1 \mathrm{CME}$
(81\%), patient chart review $(80 \%)$, and self-initiated activities $(60 \%)$ being the most common. Level $1 \mathrm{CME}$ (34\%), patient chart review (31\%), and case review conferences $(28 \%)$, were the three most likely to be mandated.

It appears that internal parties have the most direct influence on setting standards for practice improvement, , with medical director or chief of staff $(42 \%)$ and department chair $(35 \%)$ having the greatest influence. These parties may, however, be influenced by outside mandates from payers such as CMS and the Joint Commission.

Of the 83 respondents participating in practice improvement activities, 29 (35\%) indicated that they collect data on 
Table 1 Respondents by primary board

\begin{tabular}{lrrrrr}
\hline Primary board & \multicolumn{2}{c}{ Population } & & \multicolumn{2}{l}{ Sample } \\
\cline { 2 - 3 } \cline { 5 - 6 } & No. & $\%$ & & No. & $\%$ \\
\hline ABEM & 236 & 82 & & 97 & 80 \\
ABPM & 29 & 10 & & 15 & 12 \\
ABP & 22 & 8 & 9 & 7 \\
Unknown & & & & $6^{\mathrm{a}}$ & \\
Total & 287 & & 127 & \\
\hline
\end{tabular}

${ }^{a}$ Due to program error on the first day of the survey the primary board of six respondents was not captured. The six are not listed as part of the percentage returned by primary specialty

specific aspects or measures as part of their practice improvement activities. Of the 29 respondents who collect data, $24(83 \%)$ collect patient care data and 22 (76\%) collect patient outcomes data. Sixteen (55\%) collected data on medical processes, $13(45 \%)$ on communication, and 11 (38\%) on professionalism. Twenty-three (79\%) collected group data and $13(45 \%)$ individual data. Three (10\%) did not collect data. It should be noted that these represent a small sample and the estimates should be viewed with caution.

In terms of the four steps required by ABMS for practice improvement programs, $35 \%$ of the 83 respondents indicated that they conduct an initial evaluation of one or more practice activities, $37 \%$ receive feedback on their performance, $25 \%$ compare the evaluation outcome to standards, $37 \%$ develop a personal or group improvement plan, and $24 \%$ conduct a follow-up assessment of the effect of their improvement plan.

All of the respondents were asked if they are affiliated with a poison control center. Of the 100 (79\%) diplomates who indicated they were affiliated with a poison control center, $60 \%$ monitor patient outcomes, 59\% take corrective action to improve patient care, $42 \%$ assess staff competency, and $21 \%$ monitor user satisfaction. The most common activity in performance related activities at poison control centers appears to be monitoring patient outcomes and taking corrective action as needed.

\section{Potential APP Activities}

The final section of the survey asked all respondents about their perceptions of various options for an APP program. When asked about the perceived validity of potential measures for Medical Toxicology practice, respondents provided the responses displayed in Table 2 . The majority of respondents found peer review, self-improvement plans based on chart reviews, population research, and 360 evaluations to be the most valid measures. Conversely, these respondents assigned less validity to specific outcomes or patient surveys as measures.
When asked about how intrusive various activities would be to practice, most respondents rated all of the options as being somewhat to very intrusive. On a fivepoint scale with five being "Very Intrusive", the mean ratings were 3.0 for creating a new program, 3.2 for obtaining results from an existing program, 3.4 for collecting data on the outcomes of a population health program, and 3.8 for use of a program requiring entry of patient data.

When asked about potential topics for patient surveys, a majority of respondents indicated that topics relating to communication and showing respect to patients would be most valuable. These ranged from $61 \%$ for showing respect to $73 \%$ for giving clear explanations. Topics such as helpfulness, adequate time with physician, overall evaluation of visit, and effectiveness of treatment were next in importance $(45 \%$ to $51 \%$ ). Providing adequate pain relief and making patients comfortable ranked lower in importance (26\% and $25 \%$, respectively).

When asked about topics for peer review, providing accurate information about patient care and treatment (74\%) was rated as the most valuable topic. This was followed by understanding main concerns of physicians and medical staff (61\%). Getting back to physicians and medical staff in a timely manner (59\%), providing accurate information about tests (58\%), treating medical staff with respect $(55 \%)$, and helpfulness (54\%) were similar in ranking, with spending adequate time with physicians and medical staff (36\%) being ranked as least valuable.

Table 3 presents responses to the question about who would have sufficient knowledge of respondents' practice improvement activities to verify that they completed required activities. Participants were asked to indicate who from a list of potential verifiers would be knowledgeable of their practice improvement activities. Medical directors and department chairs were listed most frequently by respondents. It is important to note that approximately one third of

Table 2 Validity of potential measures

\begin{tabular}{lll}
\hline Measure & $\begin{array}{l}\text { Somewhat valid } \\
\text { to highly valid }\end{array}$ & Not valid \\
\hline Peer review & $84 \%$ & $16 \%$ \\
$\begin{array}{l}\text { Self-improvement plan } \\
\text { based on chart reviews }\end{array}$ & $77 \%$ & $23 \%$ \\
$\begin{array}{l}\text { Population research } \\
360^{\circ} \text { evaluations }\end{array}$ & $66 \%$ & $34 \%$ \\
Specific outcomes & $63 \%$ & $37 \%$ \\
Patient surveys & $45 \%$ & $55 \%$ \\
\hline
\end{tabular}

The respondents were asked to rate each measure on a fivepoint scale, with one end of the scale being 'not valid' and the other end 'highly valid.' The column labeled "Somewhat valid to highly valid" represents the three highest ratings. The column labeled "Not valid" represents the two lowest ratings. 
Table 3 Potential verifiers

\begin{tabular}{lc}
\hline Response & Percentage \\
\hline Medical director & 43 \\
Department chair & 41 \\
Practice administrator/supervisor in & 9 \\
non-hospital settings & 7 \\
Chief of staff & 2 \\
Hospital board chair or member of the board & 32 \\
None of the above would be available & \\
\hline
\end{tabular}

respondents stated that none of the positions listed would have sufficient knowledge. Respondents who answered that none of the listed positions would have sufficient knowledge indicated that they felt that a peer (ten), an administrator (nine), self-verification (six), or poison center director (four) would be knowledgeable.

\section{Discussion}

ABMS is working to assure that MOC is recognized as an important quality marker by licensing boards, insurers, hospitals, quality, and credentialing organizations, as well as the federal government. Parts 1, 2, and 3 of the MOC process are designed to measure the core competencies of medical knowledge and professionalism. Part 4, Assessment of Practice Performance, addresses the remaining four core competencies: patient care, interpersonal and communication skills, systems-based practice, and practice-based learning and improvement. The medical toxicology APP program will support diplomates' evaluation and improvement of their patient care practices. The medical toxicologists would demonstrate that they provide care that is compassionate, appropriate and effective treatment for health problems and to promote health. Moreover, they would provide evidence that they have skills that result in effective information exchange and teaming with patients, their families, and professional associates. Finally, they would demonstrate awareness of and responsibility to a larger context and systems of healthcare and that they are able to call on system resources to provide optimal care.

In evaluating the current state of practice improvement activities, we found that participation in Medical Toxicology practice improvement activities is not universal, with approximately a third of the survey participants not involved in any activity. While the first part of this survey that assessed practice settings suggested that most medical toxicologists are clinically active and encounter certain diagnoses with significant frequency, few respondents indicate that they currently collect performance improvement-related data. Most who did so participated in $\mathrm{CME}$, case-reviews, or chart reviews.
Respondents indicated that they feel peer review, selfimprovement plans based on chart reviews, and population research are the most valid measures of Medical Toxicology practice improvement. They also indicated that communication skills were important topics for patient surveys, and that providing accurate information was the most important topic for a peer survey. Other outcomes thought to be valuable for peer assessment included understanding main concerns of physicians and medical staff, timeliness of feedback, accuracy regarding test results, helpfulness to and treating medical staff with respect. Based on our results, optimal settings for the administration of practice improvement programs are hospitals and poison centers, where common ongoing activities include monitoring patient outcomes and taking corrective action.

Internal parties are viewed to have the most direct influence on practice improvement activities and would be important parties to engage in the process. Most respondents rated all of the options as being somewhat to very intrusive. In terms of potential verifiers of practice improvement activities, the response to this survey suggests that access to those with sufficient knowledge to perform this activity could pose a challenge to practice improvement programs.

There are limitations to this study. In general, surveys have a number of limitations relative to the validity and reliability of responses obtained to questions, including recall bias. We believe that the validity of the results of this survey was optimized through its development by medical toxicologists from each of the three sponsoring primary specialties and by their familiarity with the group being studied. This allowed the application of knowledge about the norms and values of this group in preparing the survey. There was no attempt to verify the results reported online by respondents. Although the number of respondents with primary board certification in Pediatrics or Preventive Medicine was small, the primary specialty of the sample of survey respondents was similar to that of the total population of Medical Toxicology diplomates. There is a potential limitation in interpreting responses on the question about who would have sufficient knowledge of respondents' practice improvement activities to verify these activities. "Medical director," considered a standard potential verifier position in similar surveys, was not further defined. The position could potentially have been interpreted as medical director of a service, poison center, or health care facility.

In conclusion, the universally accepted healthcare goals that patients experience fewer medical errors, better physician communication, and quality clinical outcomes compel board certification and maintenance of certification programs. A robust MOC program will encourage medical toxicologists to use the most current evidence-based standards and become leaders in the national movement for healthcare quality. The first broad assessment of medical toxicology diplomates 
determined the practice improvement activities that are currently available to medical toxicologists, the potential APP activities that best fit with current Medical Toxicology practice, and that the relationship between Medical Toxicology practice patterns and potential requirements to complete APP activities exists. These results will inform the development of the ABMS Medical Toxicology Assessment of Practice Performance Program.

\section{References}

1. American Board of Medical Specialties [webpage on the Internet]. MOC Competencies and Criteria [cited 2009 Jul 17]. Available from: http://www.abms.org/Maintenance_of_Certification/

2. Johnson T, Owens L (2003) Survey response rate reporting in the professional literature. Proceedings from the 58th Annual Meeting of the American Association for Public Opinion Research, Section on Survey Research Methods. Nashville, TN, May, pp 127-133 